\title{
On the role of dust storms in triggering atmospheric gravity waves observed in the middle atmosphere
}

\author{
S. K. Das ${ }^{1,2}$, A. Taori ${ }^{1}$, and A. Jayaraman ${ }^{1}$ \\ ${ }^{1}$ National Atmospheric Research Laboratory, Gadanki, Tirupati - 517 502, India \\ ${ }^{2}$ Department of Atmospheric Sciences, National Taiwan University, Taiwan \\ Received: 20 August 2011 - Accepted: 6 September 2011 - Published: 27 September 2011
}

\begin{abstract}
Lower atmospheric perturbations often produce measurable effects in the middle and upper atmosphere. The present study demonstrates the response of the middle atmospheric thermal structure to the significant enhancement of the lower atmospheric heating effect caused by dust storms observed over the Thar Desert, India. Our study from multisatellite observations of two dust storm events that occurred on 3 and 8 May 2007 suggests that dust storm events produce substantial changes in the lower atmospheric temperatures as hot spots which can become sources for gravity waves observed in the middle atmosphere.
\end{abstract}

Keywords. Atmospheric composition and structure (Aerosols and particles) - Ionosphere (Wave propagation) - Meteorology and atmospheric dynamics (Middle atmosphere dynamics)

\section{Introduction}

Atmospheric gravity waves are ubiquitous features of middle and upper atmospheric dynamical behavior. It is understood that sudden variations in thermodynamics of lower atmosphere has potential to trigger a spectrum of gravity waves. For example, several observations and theoretical investigations reveal that the tropical convections (e.g. Walterscheid et al., 2003; Alexander et al., 2006), thunderstorms and lightening (e.g. Curry and Murty, 1974; Taylor and Hapgood, 1988), weather fronts (e.g. Eckermann and Vincent, 1993) and orography (e.g. Tsuda et al., 1989; Eckermann and Preusse, 1999) are the potential sources of the observed gravity wave features in Earth's atmosphere. It is well known that any kind of sudden enhancement of lower atmospheric warming can be the cause of gravity waves propagating up to the mesospheric region (Dunkerton and Butchart, 1989). Observation from Microwave Limb Sounder suggests that the sudden enhancement of warming in the troposphere over continental landmass could be a strong potential source of gravity wave (McLandress et al., 2000). However, there are many natural phenomena in the lower atmosphere that can produce such significantly high warming effect. Among them are dust storms, which can instantaneously produce significant warming in the troposphere and disturb the vertical distribution of temperature and relative humidity. The perturbation brought into the atmosphere due to dust storms can sustain from a few hours to a few days. These storms are common in western India during premonsoon season (March-May), and the Thar Desert centered in Western India and eastern Pakistan is the primary potential source of dust storms observed over the Indian subcontinent (Deepshikha et al., 2006; Pandithurai et al., 2008).

Dust aerosols containing high amounts of iron-rich dust (like hematite) are strong absorbers of solar radiation in the UV region and hence produce significant warming within the atmosphere. The satellite observations suggest that this type of absorbing dust loading into the atmosphere is high over the Thar Desert due to frequently occurring dust storms; therefore, the Thar Desert becomes a hot spot of warming over Indian subcontinental region (Deepshikha et al., 2006). Such hot-spots produced in the lower atmosphere are sudden and forced changes that have potential to trigger gravity waves. In this paper, we examine two dust storm events which are significantly far from the summer monsoon season to avoid other dominant source contamination such as convective activity to identify any changes that can occur in the middle atmosphere. 


\section{Observations}

\subsection{Aerosol Optical Depth (AOD)}

The Moderate-Resolution Imaging Spectroradiometer (MODIS) provides a global image of retrieved aerosol parameters including aerosol optical depth, angstrom exponent, and small-mode fraction. The MODIS sensor, onboard the polar-orbiting NASA-EOS Terra spacecraft crossing over the equator at 10:30 Local Solar Time (Levy et al., 2007), continuously scans the globe in thirty-six (36) different channels in the spectral range from 0.41 to $14.4 \mu \mathrm{m}$, with three spatial resolutions, viz. $250 \mathrm{~m}$ ( 2 channels), $500 \mathrm{~m}$ (5 channels) and $1 \mathrm{~km}$ (29 channels). Aerosol parameters retrieved from MODIS observations are performed over land and oceanic surfaces by separate algorithms that use eight of these channels $(0.47-2.13 \mu \mathrm{m})$ (Kaufman and Tanrè, 1998; Hsu et al., 2004; Remer et al., 2005).

\subsection{Aerosol Index}

In addition to MODIS data, UV Aerosol Index (AI) values derived from the Ozone Monitoring Instrument (OMI) onboard the Finnish-Dutch AURA satellite are used. The AURA satellite, launched in July 2004, continuously monitors the UV absorption on a global scale, with equator overpass at 13:38 Local Solar Time. OMI detects the back scattered radiances in the near UV region; and suitable retrieval algorithm is used to derive absorbing AI, which is a qualitative measure of the presence of UV-absorbing aerosols like dust and biomass burning aerosols etc. (Torres et al., 1998, 2007; Eck et al., 2001). The combination of MODIS and OMI observations can be effectively used to identify the presence of dust loading (Kaskaoutis et al., 2008). In the present study, the OMI-AI Level 3 global-gridded product $\left(0.25^{\circ} \times 0.25^{\circ}\right.$ spatial resolution $)$ along with MODIS-derived AOD is used to detect the dust aerosols over Thar Desert.

\subsection{Dust layer}

Aerosol vertical profiles obtained from the space-borne lidar onboard the Cloud-Aerosol Lidar with Orthogonal Polarization Satellite Observation (CALIPSO) satellite are utilized to find the presence of dust layers. The lidar observes aerosol loading at $532 \mathrm{~nm}$ vertically as well as horizontally with high spatial resolution along the satellite track. From the surface to $8 \mathrm{~km}$, the vertical resolution is $30 \mathrm{~m}$ and the nominal horizontal resolution is $1 / 3 \mathrm{~km}$. CALIPSO also measures the perpendicularly polarized back scattered signal at $532 \mathrm{~nm}$ from which the vertical profile of depolarization ratio can be obtained (Vaughan et al., 2005). Angstrom coefficient is calculated from the extinction coefficients profile defined as the slope of the logarithmic of extinction coefficients versus logarithmic of wavelength in micron scales with one wavelength being $532 \mathrm{~nm}$ while other is $1064 \mathrm{~nm}$. The combined result from depolarization ratio and Angstrom exponent provides the information about the dust layer.

\subsection{Single scattering albedo}

Aerosol parameters are also measured by the Multiangle Imaging Spectroradiometer (MISR) onboard the NASAEOS Terra spacecraft, which is in Sun-synchronous orbit with equator crossing at 10:30 Local Solar Time. It is a push broom imaging instrument operating at four spectral bands centered at 446, 558, 672, and $867 \mathrm{~nm}$ in each of its nine separate cameras oriented along the orbital track with surface viewing zenith angles ranging from $\pm 70.5^{\circ}$ (Diner et al., 2008). It covers about $400 \mathrm{~km}$ swath providing a global image of aerosol properties. Aerosol retrievals provide aerosol products at $17.6 \times 17.6 \mathrm{~km}$ spatial resolution (Martonchik et al., 2002). In the present study, single scattering albedo is obtained from the MISR Level 2 product.

\subsection{Atmospheric thermal structure}

The atmospheric temperatures from 15 to $100 \mathrm{~km}$ altitudes are obtained from the data collected by Sounding of the Atmosphere using Broadband Emission Radiometry (SABER) onboard the Thermosphere Ionosphere Mesosphere Energetics and Dynamics (TIMED) satellite. The SABER data has a temperature accuracy of $\pm 1.4 \mathrm{~K}$ in lower stratosphere, $\pm 1 \mathrm{~K}$ in middle stratosphere and $\pm 2 \mathrm{~K}$ in upper stratosphere, and lower mesosphere (e.g. Remsberg et al., 2008).

\section{Results and discussion}

Multi-satellite observations are used in the present study to find the cause and effect relation between the sudden warming effect in the lower atmosphere by dust storms and the generation of the gravity waves in the middle atmosphere. The interested study region is over the dust storm region in the Thar Desert (latitudes: $20-30^{\circ} \mathrm{N}$ and longitudes: 60 $80^{\circ} \mathrm{E}$ ). Figure 1a shows the day to day variation of AOD obtained by MODIS during 1 May to 10 May 2007. Noteworthy are the two peaks in the AOD variation, indicating high aerosol loading over the selected region. Figure $1 \mathrm{~b}$ shows the spatial distribution of the AOD values. The white patches over the central part of Thar Desert are the data gap regions owing to the bright surface reflectance and/or due to the presence of clouds. Signatures of Dust storms occurred on 3 and 8 May 2007 over the Thar Desert are also found in OMIAI observations. We found that the dust storms are widely spread over the whole arid region, covering from eastern Pakistan to a large part of western India.

Simultaneous observations of aerosol vertical distribution obtained from space-borne lidar onboard the CALIPSO satellite are also analyzed to identify the height and strength of the dust layer. Figure 2a shows aerosol vertical profiles on the dust storm day 8 May 2007. The satellite track is shown 
(a)

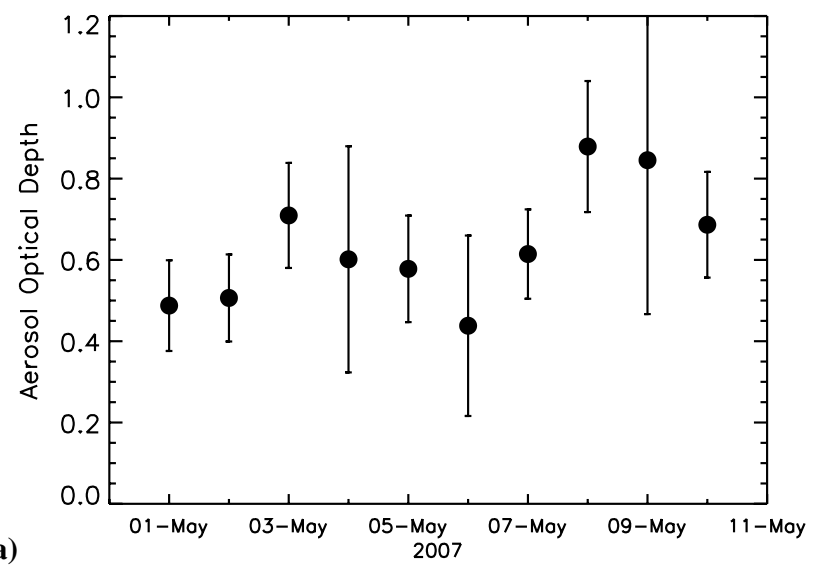

(b)

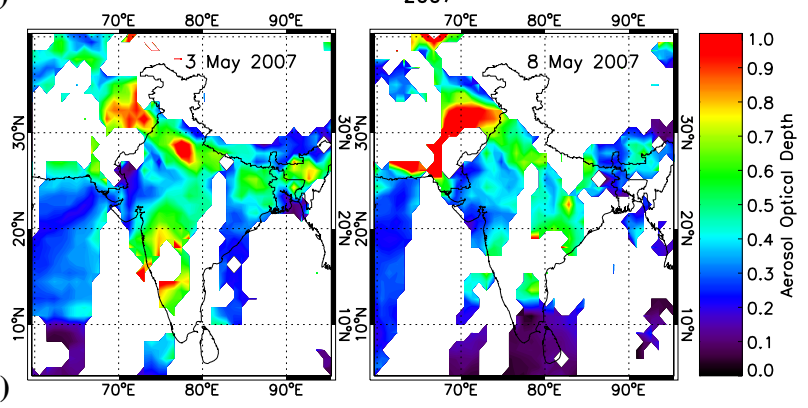

Fig. 1. (a) Day-to-day variation and (b) spatial distribution of AOD over Thar Desert (latitudes: $20-30^{\circ} \mathrm{N}$, longitudes: $60-80^{\circ} \mathrm{E}$ ) as observed by MODIS-Terra satellite.

in the insert drawn over the spatial distribution of OMI-AI showing the dust storm region. CALIPSO almost passes over the central region of this dust storm. The star and filled circle represents the central and edge region of this dust storm, respectively. The extinction coefficient profiles show a high value of about $0.11 \mathrm{~km}^{-1}$ between 2 to $5 \mathrm{~km}$ in the central region of dust storm, and this peak value becomes weaker $\left(0.02 \mathrm{~km}^{-1}\right)$ at the edge of dust storm. Therefore, one can conclude that the maximum dust loading occurred between 2 to $5 \mathrm{~km}$ lifted during the dust storm. Large dust loading can produce a sudden warming effect by absorbing solar radiation during dust storm days. To estimate the heating effect, the aerosol radiative heating rate is calculated using the observed optical properties with satellite measurements; the CALIPSO indeed observed aerosol vertical distribution over storm affected region. The rate of change of temperature $(d T / d t)$ in an atmospheric layer due to radiative heating, called radiative heating rate $\left(\mathrm{K} \mathrm{day}^{-1}\right)$, is defined as:

$\frac{d T}{d t}=-\frac{1}{\rho C_{p}} \frac{d F}{d Z}$

where $C_{p}$ is the specific heat capacity, $\rho$ is the density of air, and $d F / d Z$ is the change of radiative flux within the atmospheric layer of heights $Z$ and $Z+d Z$. Differences in heating rates with and without aerosols were computed. The aerosol heating rate is computed using SBDART (e.g. Ricchiazzi et al., 1998). This model includes all the important

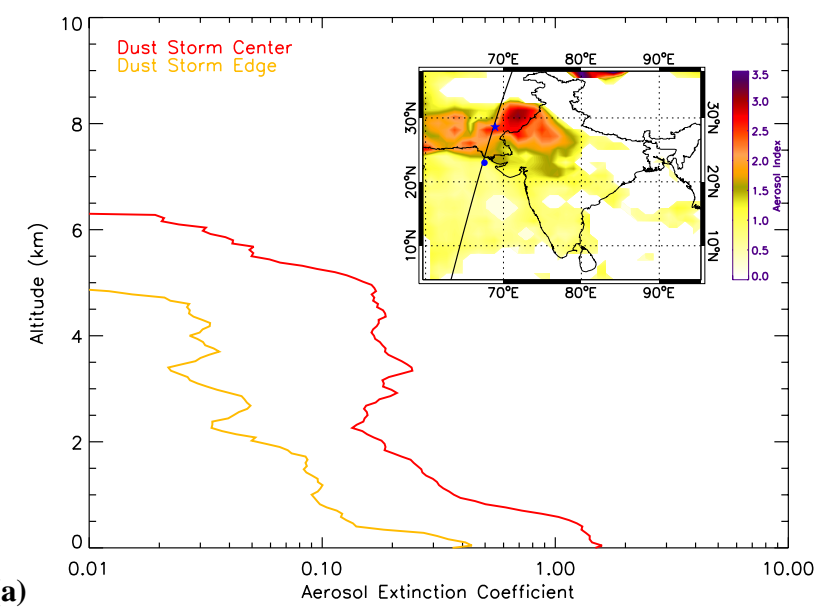

(a)

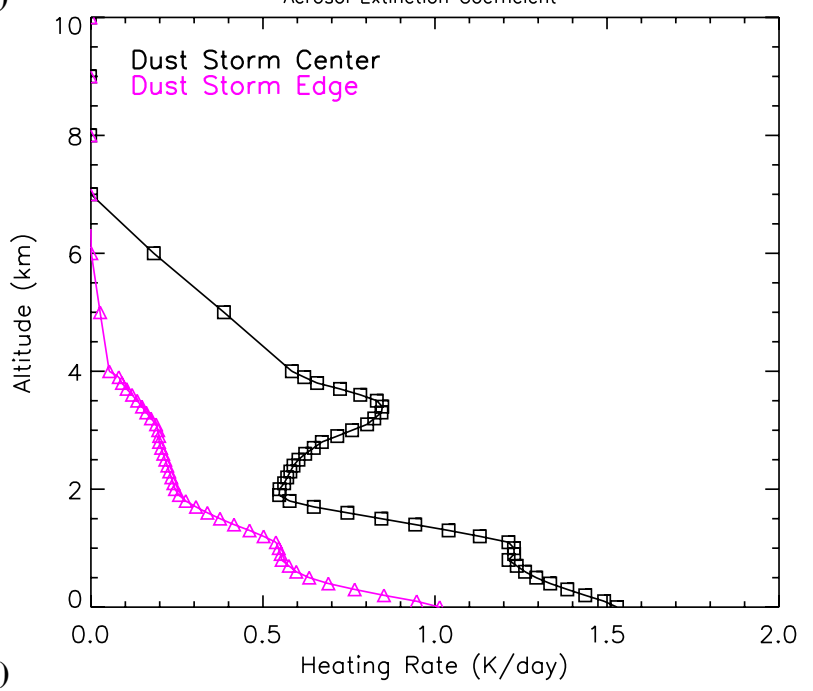

(b)

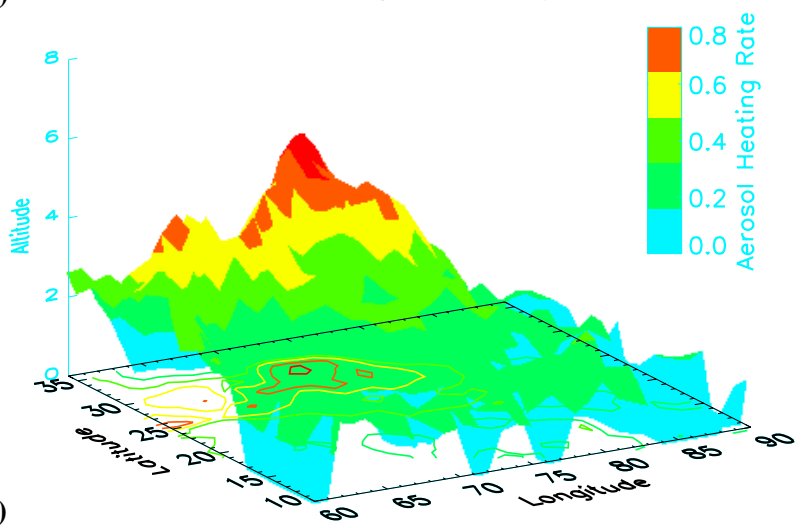

Fig. 2. (a) vertical profiles of AOD on 8 May 2007. Solid red lines show the AOD profiles at the center of the dust storm while the yellow line shows the AOD profiles at the edge of the dust storm. (b) Heating rates caused by the dust storm layer at center (black lines) and at the edge (pink lines) of the dust storm layer and (c) a 3-D plot showing the warming area with altitude.

processes that affect ultraviolet, visible, and infrared radiation field. SBDART provides the radiation fluxes at each layer of the atmosphere. In the present study, radiation fluxes 


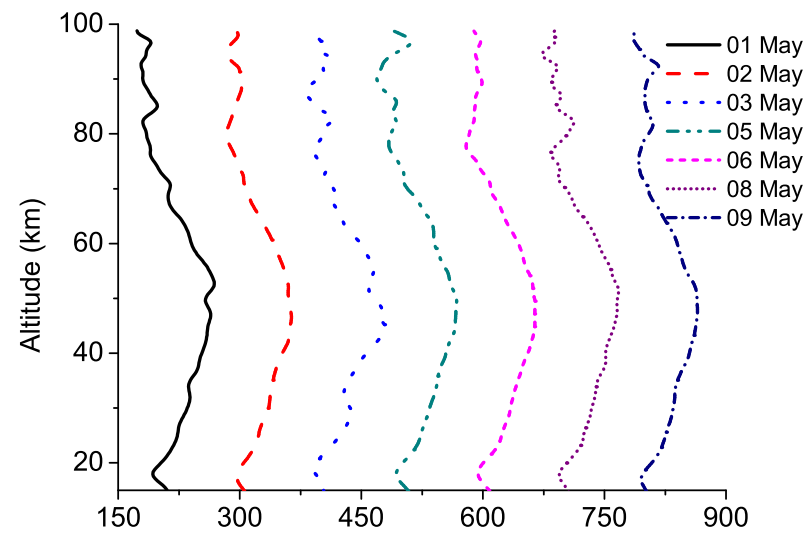

(a)

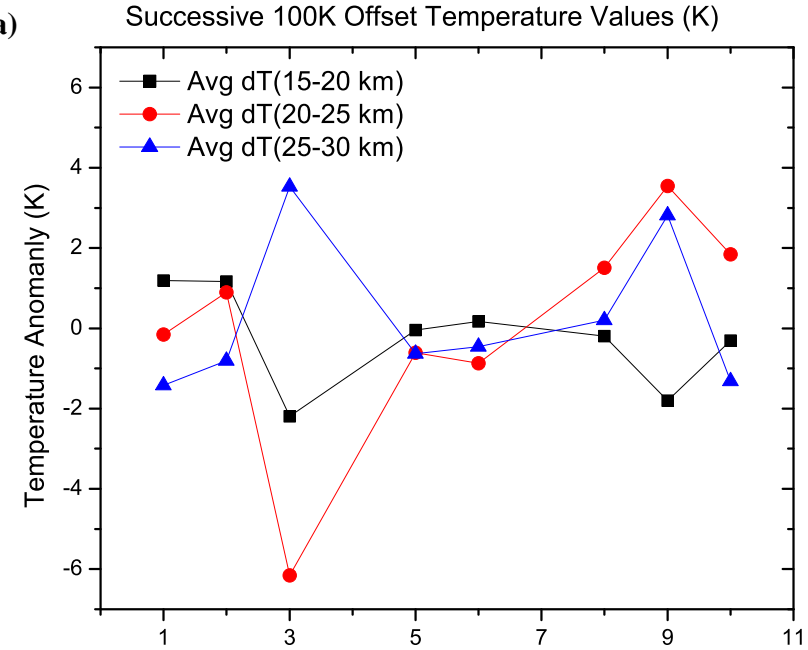

(b)

Day No. in May 2007

Fig. 3. (a) Atmospheric thermal structure variability obtained from SABER instrument onboard the TIMED satellite from 1 to 9 May 2007 (shifted by $100 \mathrm{~K}$ ) for the grid covering latitudes: 20$30^{\circ} \mathrm{N}$, and longitudes: $60-80^{\circ} \mathrm{E}$. (b) The layer averaged (15-20, 20-25 and $25-30 \mathrm{~km}$ ) temperature deviations from the mean thermal structure for 1-9 May 2007.

are calculated with and without the aerosol layer in the shortwave region $(0.25-4.0 \mu \mathrm{m})$. The aerosol optical properties like AOD, angstrom exponent, and single scattering albedo are obtained from MODIS and MISR data. Aerosol heating rate is estimated from the differences between with and without at each layer of the atmosphere. In the present study, we define the atmosphere with 65 vertically thin atmospheric layers around $100 \mathrm{~m}$ thick in the lower atmosphere. The land surface reflectance can contribute significantly in the estimation of aerosol heating effect. In the present study, surface is considered to be sand, which is a reasonable approximation over the Thar Desert.

Figure $2 b$ shows the vertical distribution of aerosol heating rate during the dust storm period over the Thar Desert. Over the central region of the dust storm the heating rate is high (near to $3.5 \mathrm{~km}$ ), which decreases as the altitude increases.
However, the value becomes insignificant at the edge of the dust storm. Both of the heating rate profiles show very low heating beyond $4 \mathrm{~km}$ and negligible above $6 \mathrm{~km}$. These results suggest that the dust storm did enhance the heating rate in the lower atmosphere concentrated in the central region of the dust storm, which decays at the edge. It is important to note that the hot spot created by the dust storm showing a differential heating of $\sim 0.8 \mathrm{~K} \mathrm{day}^{-1}$ is quiet significant and spreads over a wide area of the desert. The warming area is shown in Fig. 2c. The contour plot represents the boundary of the heating at the ground, and the surface area represents the vertical distribution of heating over the dust storm. The hot spot region (red color) of about $0.8 \mathrm{~K} \mathrm{day}^{-1}$ and about $150 \mathrm{~km}$ in diameter over the Thar Desert is clearly indicated in this figure and its influence reaches up to $6 \mathrm{~km}$. Significantly low heating rate of about $0.2 \mathrm{~K} \mathrm{day}^{-1}$, which is mostly confined within $2 \mathrm{~km}$, is found over the marine region and other tropical regions. It should be noted that the boundary layer height over the tropical region is about $2 \mathrm{~km}$ (e.g. Krishnan and Kunhikrishnan, 2004; Ganguly et al., 2006). Therefore, this large heating rate produced above the boundary layer is only over the hot spot of the dust storm region.

Such a wide spread hot spot of warming above the boundary layer could be treated as a sudden hot spot that could influence the atmospheric dynamical processes higher above. It is well known from gravity wave source mechanisms that any hot or cool spot at lower atmosphere has a potential to generate a spectrum of waves which may travel higher above. Also, most of the spectrum of waves dissipates in upper troposphere and stratosphere because of the convective instability and their interaction with winds (e.g. Fritts and Alexander, 2003), and only few of these waves propagate higher above. In order to investigate the effects, if any, we studied the atmospheric thermal structures in the altitude range from 15 to $100 \mathrm{~km}$ with the help of SABER temperature data. Figure 3a shows the average of SABER estimates for a grid with latitudes $20-30^{\circ} \mathrm{N}$ and $60-80^{\circ} \mathrm{E}$ longitudes. Large oscillatory features are observed in the temperature profiles. To identify whether any change occurred within the atmosphere, we take the deviations on the individual day temperatures at $15-20$, $20-25$, and $25-30 \mathrm{~km}$ altitude bin averages from the temperature profile average for 1-9 May 2007. Figure $3 \mathrm{~b}$ shows the temperature deviations for the above mentioned altitude bins. A clear difference is observed on 3 and 8 May 2007 from other temperature profiles. It is interesting to note that all the altitudes respond to the dust storm episode. This observation is unique and the first such observation. Following the numerical work of Vadas and Liu (2009) where they show the excitation of gravity waves by a convective body force, we take the horizontal extent of the dust storm $(\sim 150 \mathrm{~km})$ and vertical thickness of the dust layer $(\sim 6 \mathrm{~km})$ to calculate the spectrum of waves that should be generated by the dust storm. Results show that central periodicity of $\sim 120 \mathrm{~min}$ would be triggered by this dust storm. Further, as the horizontal wavelengths of most of the gravity waves observed 

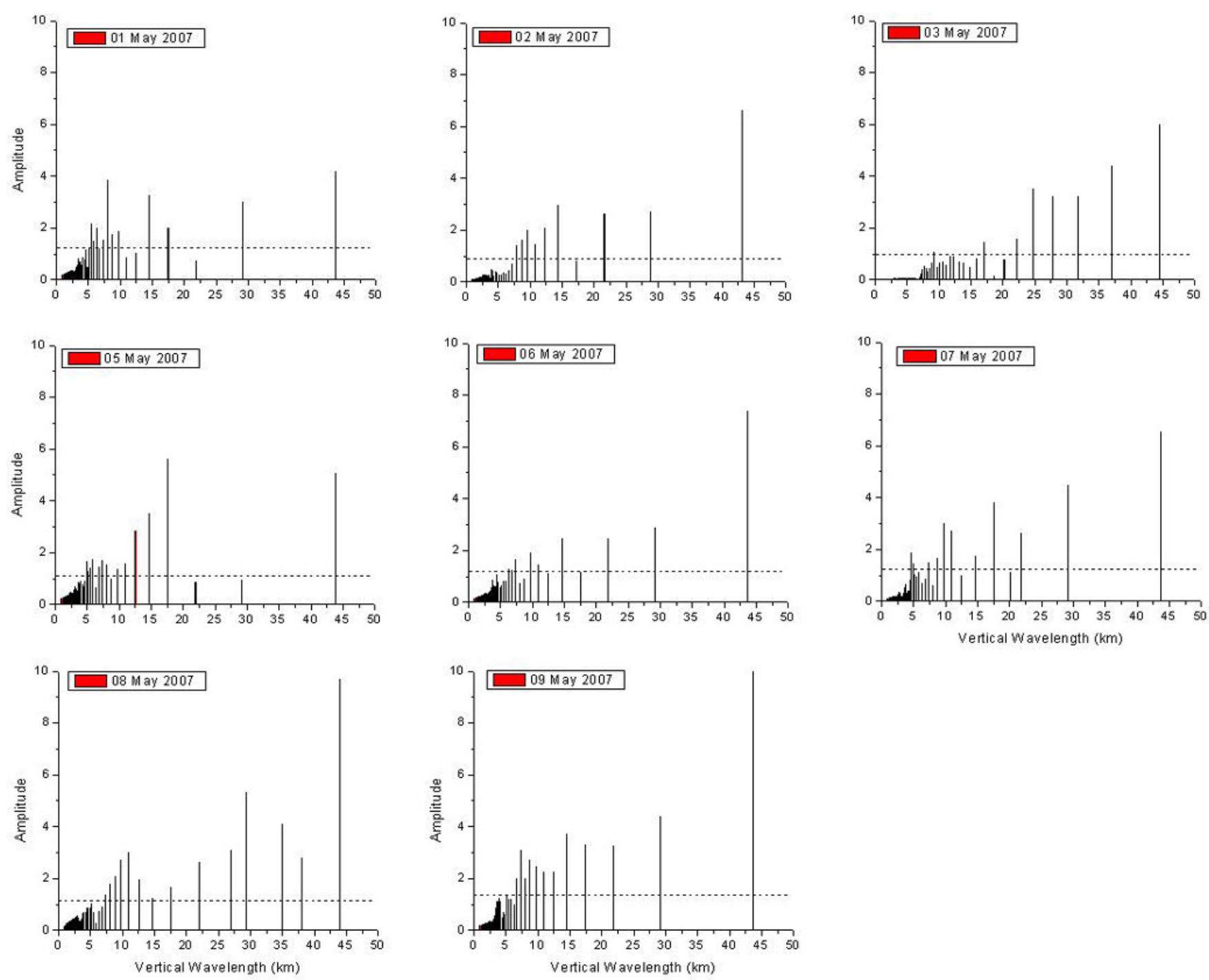

Fig. 4. The fast Fourier transform (FFT) analysis of the mean temperature deviation profiles. One may note that spectral distribution of vertical wavelength on 3 and 8 May 2007 is significantly different from other days.

at middle atmosphere generally vary from 400 to $1000 \mathrm{~km}$, the vertical wavelength observed due to this forcing should be about 15 to $40 \mathrm{~km}$. To validate this aspect, Fourier analysis of the SABER temperature profile has been carried out (Fig. 4). Horizontal dashed lines in each plot show the $90 \%$ confidence levels. It is interesting that on 3 and 8 May 2007, one notices a clear signature of specific waves with vertical wavelengths varying from $18-35 \mathrm{~km}$ that are not that strongly expressed during the other days. Further, the Fourier analysis of SABER data on 3 and 8 May 2007 for the box grid of $15-25^{\circ} \mathrm{N}$ and $70-90^{\circ} \mathrm{E}$, outside the dust storm regions, does not reveal these specific vertical wavelengths $(18-35 \mathrm{~km})$ occur. This suggests the above discussed location to be special with regards to the triggered wave modes. Also, the close resemblance between observed vertical wavelength and theoretical estimate suggests triggering of gravity wave modes due to excess localized heating caused by the dust storm. As it is also known that winds can play a role in the generation of such gravity waves, we investigated the National Centers for Environmental Prediction (NCEP) reanalysis data for the latitudes $20-30^{\circ} \mathrm{N}$ and longitudes $60-80^{\circ} \mathrm{E}$. Results show a maximum wind velocity of $\sim 2 \mathrm{~m} \mathrm{~s}^{-1}$ (from $300 \mathrm{mb}$ to $900 \mathrm{mb}$ levels) (Fig. 5) throughout this region which is very low compared to the normal winds of $\sim 6 \mathrm{~m} \mathrm{~s}^{-1}$ (e.g. Pant and Rupa Kumar, 1997) for this period. One also notices that NCEP outgoing long wave radiation (OLR) averaged for the latitude longitude grid of $20-30^{\circ} \mathrm{N}, 60-80^{\circ} \mathrm{E}$, a measure of convective activities, does not show any significant variations that may generate convective gravity waves in the atmosphere (Fig. 6). These arguments indeed confirm that winds and convection did not have a significant role in triggering the observed waves at higher altitudes and it is possibly the dust storm that was responsible for the same. 

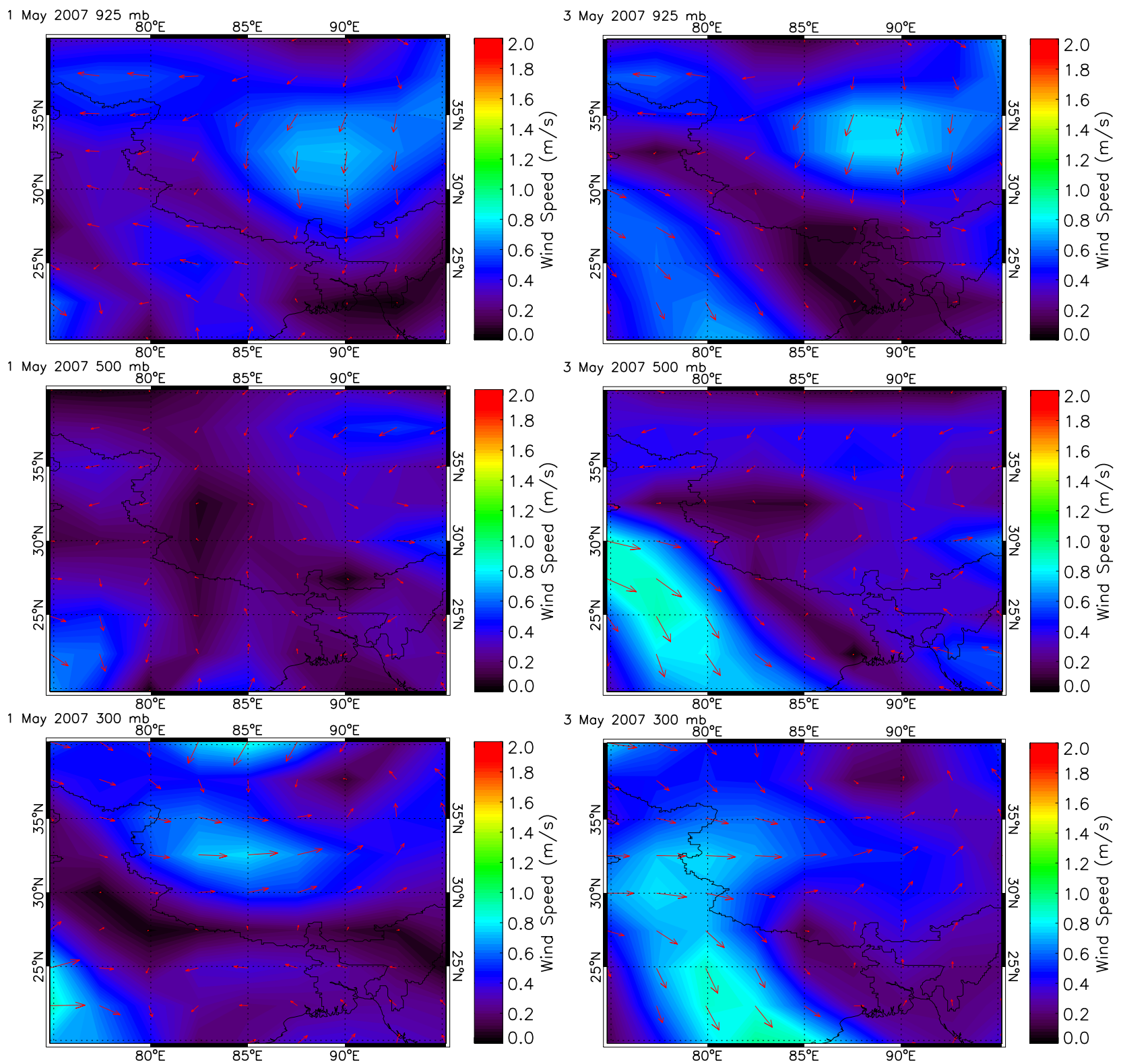

Fig. 5. The NCEP-reanalysis winds from $300 \mathrm{mb}$ to $900 \mathrm{mb}$ levels exhibiting very low winds for 3 and 8 May 2007.

Although results presented here are for only two temporally close dust storm events, they strongly suggest that dust storms can trigger some wave modes capable of coupling different atmospheric regions.

\section{Conclusions}

The present study demonstrates that the source of the middle atmospheric gravity waves can be the sudden enhancement of warming effect due to dust storm over a wide region, as observed over the Thar Desert. Multi-satellite observations were considered to identify the dust storm region during 3 and 8 May 2007 over the Thar Desert by analyzing AOD and AI data obtained from the satellite instruments MODIS and OMI, respectively. The height of the dust loading is determined from the vertical distribution of the aerosol extinction coefficient obtained from the lidar onboard the CALIPSO satellite. The calculations of aerosol heating using these satellite observation data yield new and interesting aspects regarding the source mechanism of gravity waves. Our study shows that dust storms produce a sudden enhancement of warming over a wide region which is horizontally extended to $\sim 150 \mathrm{~km}$ in the Thar Desert where the central heating is $0.8 \mathrm{~K} \mathrm{day}^{-1}$ near $3.5 \mathrm{~km}$ altitude and gradually decreases in the edge region. A significant perturbation is observed in 


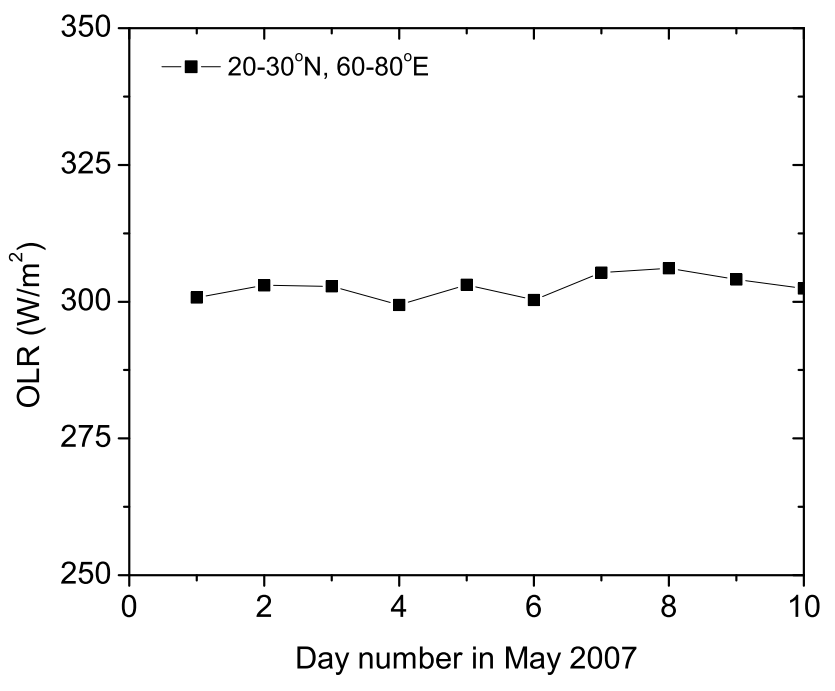

Fig. 6. The NCEP-OLR data averaged for a grid covering latitudes: 20-30 $\mathrm{N}$ and longitudes: $60-80^{\circ} \mathrm{E}$ exhibiting subdued convective activity over the region.

the middle atmospheric temperature profile as a result of the warming effect in the lower atmosphere during the two dust storms on 3 and 8 May 2007. The present study shows that lower atmospheric dust storm heating could be a potential source of the middle atmospheric gravity waves.

Acknowledgements. This work is supported by Department of Space, Govt. of India. Authors thank Harish Gadhavi, T. Narayana Rao and K. Mohan Kumar for their help and fruitful discussions. This work is partially supported by "Numerical simulation of aerosol impacts on atmospheric environment - organic aerosol mechanisms" project (Grant NSC99-2111-M-002009-MY3) and "East Asian Hydrologic cycle and its response to climate change (2/5)" (Grant NSC100-2811-M-002-041) projects under National Science Council, Taiwan.

Topical Editor C. Jacobi thanks one anonymous referee for her/his help in evaluating this paper.

\section{References}

Alexander, M. J., Richter, J. H., and Sutherland, B. R.: Generation and trapping of gravity waves from convection with comparison to parameterization, J. Atmos. Sci., 63, 2963-2977, 2006.

Curry, M. J. and Murty, R. C.: Thunderstorm generagted gravity waves, J. Atmos. Sci., 31, 1402-1408, 1974.

Deepshikha, S., Satheesh, S. K., and Srinivasan, J.: Dust aerosols over India and adjacent continents retrieved using METEOSAT infrared radiance Part I: sources and regional distribution, Ann. Geophys., 24, 37-61, doi:10.5194/angeo-24-37-2006, 2006.

Diner, D. J., Abdou, W. A., Ackerman, T. P., Crean, K., Gordon, H. R., Kahn, R. A., Martonchik, J. V., McMuldroch, S., Paradise, S. R., Pinty, B., Verstraete, M. M., Wang, M., and West, R. A.: MISR level 2 aerosol retrieval algorithm theoretical basis, JPL D11400, Revision G, Jet Propul. Lab., Pasadena, Calif., 2008.
Dunkerton, T. J. and Butchart, N.: Propagation and Selective Transmission of Internal Gravity Waves in a Sudden Warming, J. Atmos. Sci., 41, 1443-1460, 1984.

Eck, T. F., Holben, B. N., Ward, D. E., Dubovic, O., Reid, J. S., Smirnov, A., Mukelabai, M. M., Hsu, N. C., O’Neil, N. T., and Slutsker, I.: Characterization of the optical properties of biomass burning aerosols in Zambia during the 1997 ZIBBEE field campaign, J. Geophys. Res., 106, 3425-3448, 2001.

Eckermann, S. D. and Preusse, P.: Global measurements of stratospheric mountain waves from space, Science, 286, 1534-1537, 1999.

Eckermann, S. D. and Vincent, R. A.: VHF radar observations of gravity-wave production by cold fronts over southern Australia, J. Atmos. Sci., 50, 785-806, 1993.

Fritts, D. C. and Alexander, M. J.,: Gravity wave dynamics and effects in the middle atmosphere, Rev. Geophys., 41, 1003, doi:10.1029/2001RG000106, 2003.

Ganguly, D., Jayaraman, A., and Gadhavi, H.: Physical and optical properties of aerosols over an urban location in western India: Seasonal variabilities, J. Geophys. Res., 111, D24206, doi:10.1029/2006JD007392, 2006.

Hsu, C., Tsay, S., King, M. D., and Herman, M.: Aerosol properties over bright-reflecting source regions, IEEE Trans, Geosci. Remote Sens., 42, 557-569, 2004.

Kaskaoutis, D. G., Kambezidis, H. D., Nastos, P. T., and Kosmopoulos, P. G.: Study on an intense dust storm over Greece, Atmos. Environ., 42, 6884-6896, 2008.

Kaufman, Y. J. and Tanrè, D.: Algorithm for remote sensing of tropospheric aerosol from MODIS, Algorithm Theoretical Basis Documents, p. PP. 85, ATBD-MOD-02, 1998.

Krishnan, P. and Kunhikrishnan, P. K.: Temporal variations of ventilation coefficient at a tropical Indian station using UHF wind profiler, Cur. Sci., 86, 477-451, 2004.

Levy, R. C., Remer, L. A., and Dubovik, O.: Global aerosol optical properties and application to Moderate Resolution Imaging Spectroradiometer aerosol retrieval over land, J. Geophys. Res., 112, D13210, doi:10.1029/2006JD007815, 2007.

Martonchik, J. V., Diner, D. J., Crean, K. A., and Bull, M. A.: Regional aerosol retrieval results from MISR, IEEE Trans. Geosci. Remote Sens., 40, 1520-1531, doi:10.1109/TGRS.2002.801142, 2002.

McLandress, C., Alexander, M. J., and Wu, D. L.: Microwave Limb Sounder observations of gravity waves in the stratosphere: A climatology and interpretation, J. Geophys. Res., 105, 1194711967, 2000.

Pandithurai, G., Dipu, S., Dani, K. K., Tiwari, S., Bisht, D. S., Devara, P. C. S., and Pinker, R. T.: Aerosol radiative forcing during dust events over New Delhi, India, J. Geophys. Res., 113, D13209, doi:10.1029/2008JD009804, 2008.

Pant, G. B. and Rupa Kumar, K.: Climates of South Asia Belhaven Studies in Climatology, John Wiley \& Sons, Ltd. (UK), 51-70, 1997.

Remer, L. A., Kaufman, Y. J., Tanre, D., Mattoo, S., Chu, D. A., Martins, J. V., Li, R.-R., Choku, C., Levy, R. C., Kleidman, R. G., Eck, T. F., Vermote, E., and Holben, B. N.: The MODIS aerosol algorithm, products and validation J. Atmos. Sci., 62, 947-973, 2005.

Remsberg, E. E., Marshall, B. T., Garcia-Comas, M., Krueger, D., Lingenfelser, G. S., Martin-Torres, J., Mlynczak, M. G., Russell, 
J. M., Smith, A. K., Zhao, Y., Brown, C., Gordley, L. L., LopezGonzalez, M. J., Lopez-Puertas, M., She, C. Y., Taylor, M. J., and Thompson, R. E.: Assessment of the quality of the Version 1.07 temperature-versus-pressure profiles in the middle atmosphere from TIMED/SABER, J. Geophys. Res., 113, D17101, doi:10.1029/2008JD010013, 2008.

Ricchiazzi, P., Yang, S., Gautier, C., and Sowle, D.: SBDART, A research and 601 teaching tool for plane-parallel radiative transfer in the Earth's atmosphere, Bull. Am. Meteorol. Soc., 79, 21012114, 1998.

Taylor, M. J. and Hapgood, M. A.: Identification of a thunderstorm as a source of short period gravity waves in the upper atmospheric nightglow emissions, Planet. Space Sci., 36, 975-985, 1988.

Torres, O., Bhartia, P. K., Herman, J. R., Ahmad, Z., and Gleason, J.: Derivation of aerosol properties from satellite measurements of backscattered ultraviolet radiation: theoretical basis, J. Geophys. Res., 103, 17099-17110, 1998.

Torres, O., Tanskanen, A., Veiheiman, B., Ahn, C., Braak, R., Bhartia, P. K., Veefkind, P., and Levelt, P.: Aerosols and surface UV products from Ozone Monitoring Instrument observations: an overview, J. Geophys. Res., 112, D24S47, doi:10.1029/2007JD008809, 2007.
Tsuda, T., Inoue, T., Fritts, D. C., Vanzandt, T. E., Kato, S., Sato, T., and Fukao, S.: MST Radar Observations of a Sarurated Gavity Wave Spectrum, J. Atmos. Sci., 46, 2440-2447, 1989.

Vadas, S. L. and Liu, H. L.: Generation of large-scale gravity waves and neutral winds in the thermosphere from the dissipation of convectively generated gravity waves, J. Geophys. Res., 114, A10310, doi:10.1029/2009JA014108, 2009.

Vaughan, M. A., Winker, D. M., and Powell, K. A.: CALIOP algorithm theoretical basis document, part 2: Feature detection and layer properties algorithms, Rep.PC-SCI-202, 87 pp., NASA Langley Res. Cent., Hampton, Va, 2005.

Walterscheid, R. L., Schubert. G., and Brinkman, D. G.: Acoustic waves in the upper mesosphere and lower thermosphere generated by deep tropical convection, J. Geophys. Res., 108, 1392, doi:10.1029/2003JA010065, 2003. 